\title{
CARACTERIZAÇÃO DO CONSUMO DE LENHA PELA ATIVIDADE DE CERÂMICA NO ESTADO DE SERGIPE
}

\author{
Meilani Fróes Machado ${ }^{1}$, Laura Jane Gomes ${ }^{2}$, Anabel Aparecida de Mello ${ }^{2}$ \\ ${ }^{1} E_{\text {Enga. }}$ Florestal, UFS, São Cristóvão, SE, Brasil - melmei@ hotmail.com \\ ${ }^{2}$ Eng $^{\mathrm{a}}$ Florestal, Dr ${ }^{\mathrm{a}}$., UFS, São Cristóvão, SE, Brasil - laurabuturi@yahoo.com.br - anabel_mello@ yahoo.com.br
}

Recebido para publicação: 09/03/2009 - Aceito para publicação: 17/03/2010

\begin{abstract}
Resumo
Os recursos florestais têm sido utilizados de forma indiscriminada no estado de Sergipe, principalmente pela retirada de madeira nas áreas de caatinga. Esse trabalho teve como objetivos conhecer o consumo e a procedência da lenha utilizada nas fábricas de cerâmica no estado de Sergipe, quantificar o consumo de lenha, caracterizar as fontes e as formas de fornecimento da lenha e calcular o consumo específico da lenha para a atividade. O estudo foi conduzido junto a nove empresas de cerâmica situadas nos municípios de Própria, Santana do São Francisco, Neópolis, Siriri e Capela, onde foi aplicado um questionário semi-estruturado. Os resultados obtidos demonstram que metade do material combustível utilizado pelas empresas é procedente de vegetação nativa da caatinga e de espécies exóticas frutíferas sem plantio de reposição. Sendo assim, é necessário um trabalho de sensibilização e implementação de políticas públicas junto aos ceramistas, com a finalidade de estabelecer formas sustentáveis de obter o material combustível.

Palavras-chave: Recursos florestais; gestão florestal; dendroenergia.
\end{abstract}

\begin{abstract}
Firewood consumption in the ceramic activity in Sergipe State, Brazil. The forest resources have been indiscriminately used in the State of Sergipe, mainly because the wood harvested from the caatinga ecosystem. This work aimed to know the general consumption and the origin of the wood used in ceramic factories in the State of Sergipe. The main objectives were to quantify the consumption of firewood, characterize the sources and forms of supply, and calculate the specific consumption of firewood for the activity. The study was conducted in nine ceramic companies located in the Counties of Propriá, Santana do São Francisco, Neópolis, Siriri and Capela, where a semi-structured questionnaire was applied. The results showed that half of fuel material used by the companies came from the caatinga ecosystem and exotic fruit tree species. Therefore, a conscientiousness work is required, along with the implementation of public policies, in order to establish sustainable ways of obtaining the fuel material.
\end{abstract}

Keywords: Forest resource; forest management; energy of firewood.

\section{INTRODUÇÃO}

Os recursos florestais são utilizados por grande parte da população mundial para suprir necessidades diárias de energia. Segundo Teixeira (2000), a exploração desenfreada desses recursos tem proporcionado sua crescente escassez.

O desmatamento das florestas naturais para fins industriais, com base unicamente no extrativismo, traz consequências desastrosas, tanto em termos ambientais quanto socioeconômicos (SCHETTINO et al., 2000).

Goldemberg (1998) sugeriu que o cultivo da lenha em "fazendas energéticas" e seu manejo seriam particularmente significativos para prover uma base de desenvolvimento rural e a geração de emprego em países em desenvolvimento.

Sabe-se que o Brasil tem grandes vantagens para a atividade florestal, devido às excelentes condições edafoclimáticas, aliadas ao desenvolvimento tecnológico no plantio de florestas. 
No estado de Sergipe, tem-se pouco conhecimento do atual quadro de consumo e procedência de produtos energéticos que abastecem as indústrias de cerâmica. Sendo assim, julga-se necessária a realização de estudos para conhecimento da situação local das cerâmicas no tocante ao consumo de lenha, de modo a subsidiar políticas públicas que contribuam para a sustentabilidade da atividade.

Nesse sentido, o presente trabalho teve como objetivo conhecer o consumo e a procedência da lenha nas fábricas de cerâmica integrantes do projeto de Arranjo Produtivo Local (APL) do SEBRAE, desenvolvido em parceria com a Associação dos Ceramistas de Sergipe e com a Universidade Federal de Sergipe, bem como quantificar o consumo, caracterizar as fontes e as formas de fornecimento da lenha e calcular o consumo específico desse material combustível para a atividade da cerâmica, uma vez que se torna difícil a realização de projetos de base florestal para o fornecimento da matéria-prima sem dispor de tais informações.

\section{A indústria cerâmica no Brasil}

A indústria cerâmica brasileira, responsável por cerca de $1 \%$ do PIB do país, apresenta uma estrutura produtiva composta por diversos segmentos, com destaque para o setor de cerâmica vermelha (CASTRO; PACHECO, 2005).

No Brasil, convencionou-se definir o setor cerâmico em segmentos diferenciados pelos produtos obtidos e mais precisamente pelos mercados em que estão inseridos (BUSTAMANTE, 2000). Ao mesmo tempo em que domina alta tecnologia e ocupa a quarta colocação no ranking mundial de exportadores no setor de revestimentos cerâmicos, conta ainda com um sistema artesanal na cerâmica vermelha, a chamada cerâmica estrutural.

Segundo dados da ANICER (2003), as indústrias de cerâmica vermelha distribuem-se por todo o país, pulverizadas em micro e pequenas empresas, quase sempre de organização simples e familiar. A distribuição das unidades produtoras é controlada pela ocorrência dos depósitos de argila. O número de empresas relacionadas ao setor de olarias e cerâmicas no Brasil, em 2003, era de aproximadamente 12 mil, as quais geraram 650 mil empregos diretos, 2 milhões de indiretos e um faturamento anual de $\mathrm{R} \$ 6$ bilhões.

O processo produtivo é caracterizado pelo grande consumo energético e por um expressivo impacto ambiental, movimentando cerca de 60.000.000 toneladas de matéria-prima ao ano, com reflexos nas vias de transportes e no meio ambiente de lavra de argila (BUSTAMANTE, 2000).

As cerâmicas utilizam grandes quantidades de energia, assim como a indústria de aço, cimento e vidro. Todas essas indústrias caracterizam-se por utilizarem altas temperaturas nos fornos e fornalhas, sendo que o custo da energia utilizada nos processos representa um percentual significativo no total dos custos de produção (AGRAFIOTIS; TSOUTSOS, 2001).

Em comparação com o setor de cimento, que, conforme o Balanço Energético Nacional (BRASIL, 2000), utiliza predominantemente fontes derivadas do petróleo e eletricidade, o setor cerâmico tem na lenha sua principal fonte energética, o que acaba contribuindo para manter o atraso tecnológico desse setor (CASTRO; PACHECO, 2005).

Para a região Nordeste não foram encontrados estudos recentes que abordem o consumo do combustível utilizado no setor cerâmico. Uma pesquisa feita em 1992, no Rio Grande do Norte, estado escolhido por representar, com boa margem de segurança, a realidade ambiental, social e econômica do Nordeste, indicou que $52 \%$ do total de energia consumida nos setores industrial/comercial são procedentes de material lenhoso da caatinga, tendo no ramo cerâmico o maior consumidor (LEHTONEN, 1992).

\section{Matriz energética e sustentabilidade da atividade cerâmica no Nordeste}

A lenha é provavelmente o energético mais antigo usado pelo homem e continua tendo grande importância na matriz energética brasileira. Ela pode ser de origem nativa ou de reflorestamento, e seus principais constituintes são: celulose (41-49\%), hemicelulose (15-27\%) e lignina (18-24\%). Recebe a denominação de "energia dos pobres", por ser parte significativa da base energética dos países em desenvolvimento, chegando a representar até $95 \%$ da fonte de energia em vários países. Nos países industrializados, a contribuição da lenha chega a um máximo de $4 \%$. 
Brito; Barrichelo (1978) indicam o poder calorífico, o teor de umidade, a massa específica e a análise imediata como propriedades importantes da madeira para sua utilização como combustível.

Segundo Doat (1977), o poder calorífico de um corpo é a quantidade de calor liberada pela combustão de uma unidade de massa desse corpo e pode ser expresso em calorias por grama ou quilocalorias por quilograma. Esse mesmo autor definiu o poder calorífico superior (PCS) como aquele em que a combustão se efetua em volume constante e no qual a água formada durante a combustão é condensada.

Para Brito (1986), a variação do poder calorífico superior da madeira está entre $14.651 \mathrm{~kJ} / \mathrm{kg}$ e $20.930 \mathrm{~kJ} / \mathrm{kg}$. Kollmann; Côté (1968) relataram que o poder calorífico médio para as madeiras situa-se em torno de $18.837 \mathrm{~kJ} / \mathrm{kg}$ a $0 \%$ de umidade, e que esse valor baixa para $15.906 \mathrm{~kJ} / \mathrm{kg}$ a $20 \%$ de umidade.

A redução da umidade na madeira é desejável não somente para diminuir os custos de manejo e transporte, mas também para aumentar o valor da madeira como combustível. Por isso, nas regiões tropicais, a madeira é cortada 3 a 4 meses antes de ser queimada, enquanto que nas regiões temperadas a madeira deve ser cortada entre 6 e 12 meses antes. Tais períodos são suficientes para diminuir a umidade da madeira em 25 a $30 \%$ e aumentar o seu poder calorífico para até $4000 \mathrm{kcal} / \mathrm{kg}$.

A análise imediata da madeira fornece os teores de carbono fixo, matérias voláteis e cinzas, ou, ainda, segundo Brito; Barrichello (1978), a porcentagem do material residual (cinzas) e dos materiais que se queimam no estado gasoso (material volátil) e no estado sólido (carbono fixo).

A madeira contém uma quantidade insignificante de enxofre, não causando poluição do ar com compostos sulfurosos, ao contrário da maioria dos carvões minerais e óleos pesados. $\mathrm{O}$ teor de cinzas corresponde, geralmente, a menos que $1 \%$ em peso, sendo maior na casca do que na madeira (BRITO; BARRICHELO, 1979).

A baixa eficiência da energia de biomassa é um aspecto relevante a ser considerado, cuja melhoria tem sido creditada à modernização de equipamentos e motores e à substituição de fontes menos eficientes, dentre elas a lenha, nos setores de geração residencial, comercial, agropecuário e industrial. Essa baixa eficiência da lenha deve-se a vários aspectos: a heterogeneidade do material utilizado; o uso de materiais não selecionados para produção de energia; o uso de material in natura e o pouco uso de "pellets", briquetes, dentre outras formas mais adequadas.

O tipo de forno também vai influenciar na eficiência e consumo de lenha. Por exemplo, em Sergipe, são encontrados dois tipos de fornos, a saber:

1. Fornos semicontínuos do tipo Hoffmann, que são divididos em compartimentos, denominados poços ou câmeras. A queima se dá poço a poço, ou seja, enquanto um está queimando, os posteriores estão na fase de aquecimento, aproveitando o calor da queima, e os anteriores estão resfriando, com o uso de ar ambiente.

2. Fornos intermitentes, que apresentam inconvenientes, como o elevado consumo de combustível e uso de mão de obra, e o desgaste da estrutura, devido às variações sucessivas de calor e frio. Apresentam, porém, vantagens, como o baixo custo de instalação e a facilidade de execução.

Mesmo assim, a lenha ainda tem, no mundo e no Brasil, uma grande importância como fonte de produção de energia. Em 2003, por exemplo, o setor residencial e a produção de carvão consumiram 25,7 e 34 milhões de toneladas de lenha, respectivamente a $31 \%$ e $41 \%$ da produção de lenha brasileira (SBS, 2005).

É crescente a substituição da lenha de mata nativa por lenha de reflorestamento, sendo o eucalipto a principal árvore cultivada para esse fim (INFOENER, 1998), porém no Nordeste ainda é alarmante o uso de espécies do bioma caatinga sem planos de manejo.

Muitas das espécies vegetais da caatinga estão atualmente ameaçadas de extinção, principalmente pela forte pressão extrativista de madeira para produção de carvão e/ou materiais de construção. Na vegetação original, era comum a ocorrência de árvores com tamanhos maiores e também um número maior de espécies e indivíduos, inclusive de madeira nobre. Além da exploração realizada pelo pequeno produtor, indústrias, como padarias e cerâmicas, também foram grandes consumidoras de madeira, lenha e carvão provenientes desse bioma. Em relação ao estado original, a caatinga se encontra empobrecida, devastada, mais aberta do que era, com árvores baixas, de caule fino, às vezes apenas de tamanho e forma arbustivos, e com poucas espécies (MAIA, 2004). 


\section{MATERIAL E MÉTODOS}

\section{Coleta e análise das informações}

Com base no cadastro de produtores associados junto ao SEBRAE, integrantes do Projeto Arranjos Produtivos Locais, foi realizada a coleta dos dados nos meses de outubro a novembro de 2006. Foram avaliadas nove indústrias de cerâmica, nos municípios de Propriá (4), Santana do São Francisco (1), Neópolis (1), Siriri (2) e Capela (1), todas ligadas à produção de blocos e tijolos.

Um questionário semiestruturado foi aplicado em entrevista direta com o proprietário ou funcionário vinculado ao empreendimento, com o qual buscou-se identificar algumas características de cada cerâmica, como volume de lenha consumido mensalmente, preço e origem da lenha, espécies utilizadas, produção de blocos por estéreo de lenha, interesse em implantação de projetos de reflorestamento, qual espécie implantaria e principais problemas enfrentados pela atividade cerâmica. A identificação das empresas neste trabalho foi feita por números, a fim de manterem-se os nomes preservados. Os dados foram tabulados em uma planilha Excel e calculados os somatórios e as médias.

O consumo específico, relação entre a quantidade de energia consumida e o produto obtido, foi calculado segundo Zakia; Verslype (1992):

$$
\text { Consumo específico }=\frac{\text { st de lenha } / \text { mês }}{\text { milheiro } / \text { mês }}
$$

\section{RESULTADOS E DISCUSSÃO}

\section{Produção de cerâmica}

A produção total das nove cerâmicas pesquisadas é de aproximadamente 7,6 milhões de blocos/mês. A maior produção está no município de Propriá, com 4,03 milhões de blocos/mês, seguido dos municípios de Siriri e Capela, com 1,9 milhões de blocos/mês e 1,5 milhões de blocos/mês, respectivamente. As menores produções encontradas estão em Santana do São Francisco e Neópolis, com 200 mil blocos/mês em cada município (Figura 1).

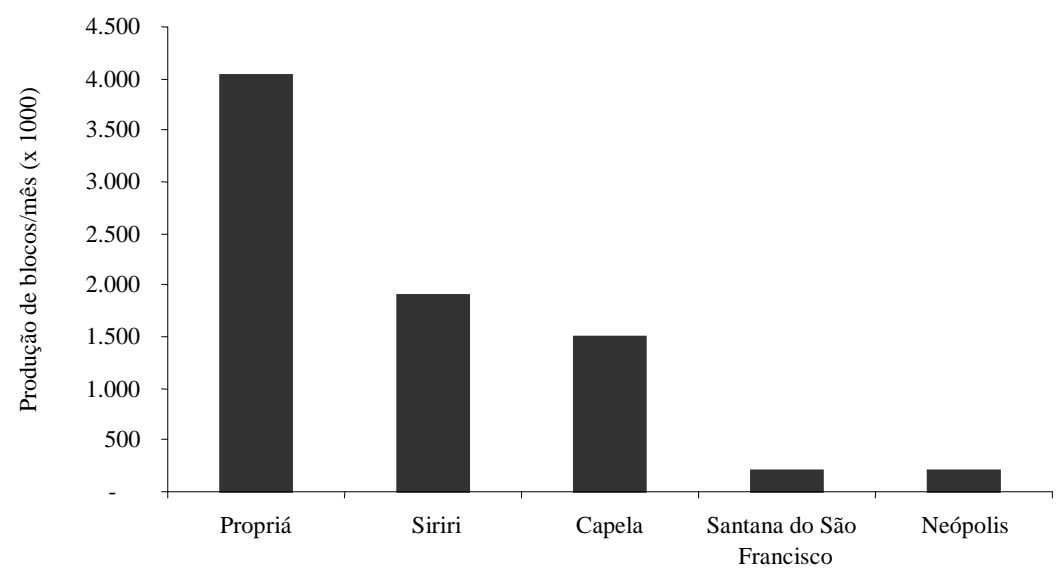

Figura 1. Produção de blocos/mês encontrada nos municípios de Propriá, Siriri, Capela, Santana do São Francisco e Neópolis, estado de Sergipe, 2006.

Figure 1. Blocks per month production found at Propriá, Siriri, Capela, Santana do São Francisco and Neópolis locality, Sergipe State, 2006.

\section{Procedência e consumo do material combustível utilizado}

O material combustível utilizado pelas cerâmicas é procedente de várias origens, sendo 53\% da floresta nativa, 24\% costaneira de Pinus, $12 \%$ bambu e 11\% Eucalyptus. 
O uso de lenha de espécies nativas ocorre em todos os municípios (Tabela 1) e as espécies citadas foram: angico, catingueira, juazeiro, jurema, marmeleiro e sabiá. Nenhum estudo científico foi feito para identificação dessas espécies, sendo considerado neste trabalho apenas os nomes "vulgares" citados pelos entrevistados.

Tabela 1. Consumo e procedência do material combustível utilizado pelas cerâmicas por município. Table 1. Consumption and origin of the firewood used by the ceramic material by municipality.

\begin{tabular}{lcccc}
\hline \multirow{2}{*}{ Cerâmica } & \multicolumn{4}{c}{ Consumo (st/mês) } \\
\cline { 2 - 5 } & Eucalyptus & Pinus & Nativa & Bambu \\
\hline Propriá & 320 & 600 & 235 & 545 \\
Siriri & 77 & 525 & 248 & - \\
Santana do São Francisco & - & - & 120 & - \\
Capela & - & - & 1.700 & - \\
Neópolis & 100 & - & 300 & - \\
\hline Total & 497 & 1.125 & 2.603 & 545 \\
\hline
\end{tabular}

Os ceramistas fizeram referência ao consumo de espécies denominadas "frutíferas", com menção à mangueira (Mangifera indica L.) e ao cajueiro (Anacardium occidentale L.), espécies exóticas plantadas ${ }^{1}$ em sítios ou chácaras, que vêm sendo devastadas sem obrigatoriedade de reposição de plantios.

Nenhum entrevistado comprovou a procedência da lenha obtida da caatinga como proveniente de áreas com plano de manejo. Apesar de permitida a exploração da caatinga, esta deverá ocorrer mediante um plano de manejo, e quando originada de autorização de desmatamento para uso alternativo do solo, deverá ser realizada a devida reposição florestal. Sabe-se que nem o IBAMA nem o órgão ambiental estadual em Sergipe possuem o procedimento de realização de plano de manejo desse bioma, procedimento este que já faz parte da rotina dos órgãos ambientais nos estados de Pernambuco e Paraíba.

O consumo total de lenha das cerâmicas apresenta um volume de cerca de 497 st/mês de madeira de Eucalyptus, 1.125 st/mês de costaneira de Pinus e 2.603 st/mês de madeira proveniente da floresta nativa, totalizando $4.225 \mathrm{st} / \mathrm{lenha} / \mathrm{mês}$.

O fato de o consumo de material lenhoso proveniente de "frutíferas" não ser um ato ilícito, de acordo com o Código Florestal, isso não o torna menos preocupante, visto que qualquer exploração feita sem licença de desmatamento é ilegal.

Uma das localidades citadas por um dos entrevistados como fornecedora de espécies nativas foi Capela (povoado Pirunga), sendo que esse município apresenta fragmentos florestais significativos de Mata Atlântica. As toras de Eucalyptus e a costaneira de Pinus são procedentes de plantações do estado da Bahia.

No município de Propriá, o bambu tem sido utilizado para a "pega" dos fornos, pois essa espécie alcança altas temperaturas de forma mais rápida e eficiente. Após a "pega" com bambu, a lenha (procedente de costaneira de Pinus, Eucalyptus e/ou nativa) é colocada nos fornos. O bambu é procedente dos municípios de Laranjeiras, Pedra Branca e Rosário, localizados no estado de Sergipe.

Embora não se pense no bambu como uma solução exclusiva para os problemas relacionados ao meio ambiente e/ou a diminuição acentuada de recursos florestais, ele pode ser considerado e estudado como um material alternativo e de baixo custo a ser explorado. A produção de colmos é rápida, sem a necessidade de replantio. Particularmente para o Brasil, país que utiliza intensamente a biomassa para atendimento de suas necessidades energéticas, o bambu poderá ser uma importante alternativa (BRITO et al., 1987; PEREIRA, 2001).

\section{Preço do material combustível}

O preço do material combustível de Eucalyptus sofre variações de município para município, sendo que em Propriá o valor chega a $\mathrm{R} \$ 56,00$ o estéreo (Tabela 2). Essa variação deve-se ao fato de que, quanto maior a distância da fonte produtora, mais caro fica o produto, em decorrência dos gastos com transporte.

Deste modo, o fator que justifica a preferência pela lenha de espécies da caatinga é o seu custo final. Apesar de variar entre municípios, R \$ 23,00/st em Siriri (preço máximo) e 8,00/st em Neópolis

\footnotetext{
${ }^{1}$ Não foi possível calcular separadamente as espécies exóticas cajueiro e mangueira das espécies nativas da caatinga, sendo indicadas neste estudo também como nativas.
} 
(preço mínimo), comparando-a com o valor do Eucalyptus e costaneira de Pinus, a lenha de vegetação nativa apresenta-se com menor preço justamente por se tratar de uma atividade sem controle de reposição florestal, não apresentando custos de produção ou de manejo.

Tabela 2. Preço médio pago pelo estéreo de lenha, por tipo e município.

Table 2. Average price by stere of firewood, by type and municipality.

\begin{tabular}{lcccc}
\hline \multirow{2}{*}{ Cerâmica } & \multicolumn{4}{c}{ Preço $(\mathbf{R}$ /st $)$} \\
\cline { 2 - 5 } & Eucalyptus & Pinus & Nativa & Bambu \\
\hline Propriá & 56 & 35 & 18 & 19 \\
Siriri & 35 & 31 & 23 & - \\
Santana de São Francisco & - & & 15 & \\
Capela & - & - & 16 & - \\
Neópolis & 42 & - & 8 & - \\
\hline
\end{tabular}

\section{Tipos de fornos}

Das nove cerâmicas visitadas, seis utilizavam o forno tipo Hoffmann e três utilizavam o forno tipo intermitente. Os fornos semicontínuos do tipo Hoffmann foram encontrados nos municípios de Propriá (3), Siriri (2) e Capela (1). Os fornos intermitentes, encontrados nas cerâmicas de Neópolis (1), Santana do São Francisco (1) e Propriá (1), são os mais simples, sendo preparado um lote de cada vez.

\section{Consumo específico}

O consumo específico médio encontrado nas cerâmicas estudadas foi de 0,98 st/milheiro. É importante ressaltar que esse valor representa uma média, incluindo as variáveis: material combustível e os dois tipos de fornos utilizados pelas cerâmicas. Esse resultado é considerado satisfatório quando comparado ao valor obtido em um estudo realizado no Rio Grande do Norte (ZAKIA; VERSLYPE, 1992), onde foi constatado um consumo específico de 2,9 st/milheiro para a produção de cerâmica de tijolos em forno intermitente.

O material lenhoso é um dos fatores que causa variação no consumo específico, pois espécies com maior poder calorífico são mais eficientes e geram um menor consumo específico (ZAKIA; VERSLYPE, 1992). Os tipos de fornos, intermitente e semicontínuo, também causam diferencial no resultado final.

\section{Principais problemas enfrentados pelos ceramistas}

Alguns problemas foram mencionados na atividade da cerâmica, sendo que os gastos com energia elétrica, juntamente com a falta de mão de obra qualificada, foram citados por $63 \%$ dos entrevistados.

Outras questões, como juros elevados, falta de incentivos fiscais, burocracia para legalização da atividade junto aos órgãos competentes, preço da lenha e áreas para extração de argila, foram abordadas com menor frequência pelos entrevistados.

É importante salientar que a procedência da lenha, assim como a preocupação quanto à reposição florestal, não parece ser assunto que esteja à frente das preocupações no ramo dos ceramistas. Apenas dois entrevistados de Propriá citaram essa questão como sendo fonte de preocupação.

\section{CONCLUSÕES}

- A base energética das cerâmicas entrevistadas encontra-se num quadro insustentável, pois metade da demanda é dependente de lenha procedente de vegetação nativa da caatinga sem plano de manejo e/ou de espécies exóticas frutíferas sem plantio de reposição.

- O Eucalyptus e a costaneira de Pinus, embora não sejam os meios mais utilizados como fonte de energia pelos ceramistas entrevistados, são os mais indicados a desempenhar tal função. Por outro lado, o alto preço do Eucalyptus, decorrente da distância da fonte produtora, não tem sido um atrativo aos ceramistas, que acabam encontrando nas espécies de vegetação nativa uma alternativa mais viável economicamente.

- É necessário um amplo trabalho de sensibilização junto aos ceramistas, esclarecendo-os sobre as questões aqui apresentadas. O segmento deve buscar organização e diálogo, com a finalidade de 
estabelecer formas sustentáveis de obter o material combustível, como, por exemplo, investir na produção florestal local com espécies de rápido crescimento para suprir tal demanda.

- Os órgãos ambientais atuantes no estado de Sergipe devem implantar políticas públicas com a finalidade de melhorar a eficiência dos instrumentos de controle da reposição florestal, bem como fiscalização e procedimentos rotineiros, para que se torne possível a realização de planos de manejo da caatinga.

\section{REFERÊNCIAS}

AGRAFIOTIS C.; TSOUTSOS, T. Energy saving technologies in the European ceramic sector: a systematic review. Applied Thermal Engineering, Oxford, v. 21, n. 12, p. 1231-1249, Aug. 2001.

ANICER - Associação Nacional da Indústria Cerâmica. Disponível em: <http://www.anicer.com.br>. Acesso em: 1/11/2006.

BRASIL. Ministério de Minas e Energia. Balanço Energético Nacional. Brasília, 2000. 154 p. Disponível em: <http://www.ipea.gov.br/pub/td/td_2000/td0719.pdf〉. Acesso em: 8/12/2006.

BRITO, J. O.; BARRICHELO, L. E. G. Usos diretos e propriedades da madeira para geração de energia. Piracicaba: IPEF, 1979. 6 p. (Circular Técnica, 52).

BRITO, J. O. Madeira para energia: a verdadeira realidade do uso de recursos florestais; In: $5^{\circ}$ CONGRESSO FLORESTAL BRASILEIRO, 5., 1986, Olinda. Anais... São Paulo: Sociedade Brasileira de Silvicultura; 1986. p. 188-193.

BRITO, J. O.; TOMAZELLO FILHO, M.; SALGADO, A. L. de B. Produção e caracterização do carvão vegetal de espécies e variedades de bambu. IPEF, Piracicaba, n. 36, p. 13-17, 1987.

BUSTAMANTE, G. M.; BRESSIANI, J. C. A indústria cerâmica brasileira. Revista Cerâmica Industrial, São Paulo, v. 5, n. 3, p. 31-36, 2000.

CASTRO, N.; PACHECO, C. Análise das possibilidades de expansão do uso do gás natural na indústria cerâmica brasileira. Rio de Janeiro: IE - UFRJ, 2005.(BGN, n²2).

DOAT, J.; Le puovoir calorifique des bois tropicaux. Bois et Forêts des Tropiques; Nogent-sur-Marne, n. 172, p. 33-48, 1977.

GOLDEMBERG, J; USP; Energia, meio ambiente \& desenvolvimento. São Paulo: Editora da Universidade de São Paulo,1998. 125 p.

INFOENER - Sistema de Informações Energéticas - Banco de dados de biomassa no Brasil. Disponível em: 〈http://infoener.iee.usp.br/cenbio/biomassa.htm>. Acesso em: 27/9/2006.

KOLLMANN, F.; CÔTÉ JR., W. A. Principles of wood science and technology. I - solid wood. New York: Springer Verlag, 1968. 592 p.

LEHTONEN, P. Impacto econômico do recurso florestal na economia do Rio Grande do Norte. Projeto PNUD/FAO/BRA/87/007. Natal: [s.n.], 1992. (Circular Técnica, 15).

MAIA, G. N. Caatinga: árvores e arbustos e suas utilidades. São Paulo: D\&Z Computação Gráfica e Editora, 2004.

SCHETTINO, L. F.; SOUZA, A. L.; SILVA, M. L.; BRAGA, G. M.; REZENDE, J. L. P.; SOUZA, A. P. Diagnóstico para gestão florestal sustentável no Espírito Santo. Revista Árvore, Viçosa, MG, v. 24, n. 4, p. 445-456, 2000.

SOCIEDADE BRASILEIRA DE SILVICULTURA (SBS). Contribuições ao plano nacional de energia 2006-2010, no componente florestas energéticas. Disponível em: <http://www.sbs.org.br/destaques_contribuicoes.html>. Acesso em: 10/10/2006.

TEXEIRA, D. Estado de la informacion sobre madera para energia. 2000. Disponível em: <http://www.fao.org/DOCREP/006/AD399S/AD399s07.htm>. Acesso em: 27/9/2006.

ZAKIA, M. J. B.; VERSLYPE, C. Guia para levantamento do consumo e fluxo de produtos florestais. Fortaleza: PNUD/FAO/IBAMA, 1992. 77 p. 
